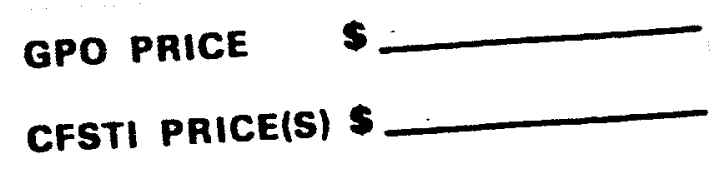

Hard copy $(\mathrm{HC}) \frac{2,00}{150}$
Microfiche (MF)

ก1 853 sun 05

\begin{abstract}
AN INSTRUMENT FOR THE RAPID MEASUREMENT OF SURFACE DEFORMATIONS OF A 210-FT RADIO

TELESCOPE
\end{abstract}

M.J. PUTTOCK and H.C. MINNETT
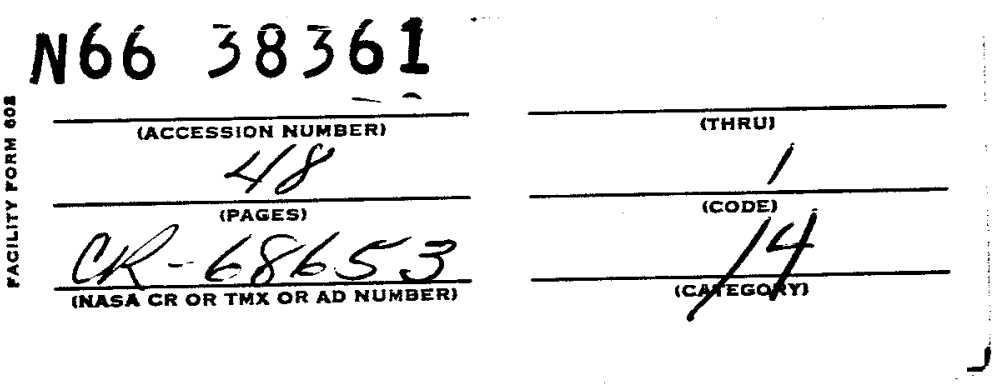

Radiophysics Laboratory

Commonwealth Scientific and Industrial Research Organization Australia

RPP 966

September 1965 
AN INSTRUMENT FOR THE RAPID MEASUREMENT OF SURFACE DEFORMATIONS OF A 210-FT RADIO

TELESCOPE

M.J. PUTTOCK and H.C. MINNETT

Radiophysics Laboratory

Commonwealth Scientific and Industrial Research Organization Australia

RPP 966

September 1965 


\title{
AN INSTRUMENT FOR THE RAPID MEASUREMENT OF SURFACE DEFORMATIONS OF A 210-FT RADIO TELESCOPE
}

\section{M.J. PUTTOCK and H.C. MINNETT}

\begin{abstract}
Lambda$ description is given of an instrument desinned for rapid measurement of the surface deformations of the $210-f t$ radio telescope at Parkes, Australia. The performance of the instrument is assessed, particularly the accuracy of measurements of surface deflections which occur when the dish is tilted from the zenith. It is shown that this accuracy corresponds to about $1 \mathrm{~mm}$ at the rim of the dish for a zenith angle of $60^{\circ}$ and is substantially less for smaller zenith angles and lor positions on the surface at smaller radii from the vertex.
\end{abstract}

Tnformation is also given on the facility provided by the instrument for the rapid measurement of other important features such as fecd position and deflection,

Manuscript received

M.J. Puttock is with the Division of Applied Physics, CSIRo, Sydney, Australia.

II.C. Minnett is with the Division of Radiophysics, CSIRO, Sydney, Nustralia. 
relationship of the dish to the vertical and the effect on the dish axis of irregularitics in the azimuth track.

\section{INTRODUCTION}

The $210-\mathrm{ft}$ radio telescope at the Australian National Radio Astronomy Observatory, Parkes, N.S.W., which is part of the Division of Radiophysics, CSIRO, began operations in 0ctober, 1961. It was designed by Frecman, Fox and l'artners, London, to a specification which required that the dish surface should be of paraboloidal form within the permissible crror of \pm 0.5 inch $( \pm 12 \mathrm{~mm})$. The nost important contribution to the performance of such a tclescope is the quality of the reflector and iend as a radio aerial. This quality depends to a r: large extent on the accuracy with which the dish surface conforms to a paraboloid of revolution. Design studies showed that somewhat better surface accuracy than that originally specified should bc possible and after the design had been finalized the constructors, Maschinenfabrik-Augsburg-Nurnberg A.G. (AiMN) were asked to attempt to adjust the surface to slightly smaller tolerances namely, $\pm 3 \mathrm{~mm}$ over the central $30 \mathrm{ft}$ diameter solid portion and $\pm 9 \mathrm{~mm}$ over the mesh surface beyond. These figures were with the telescope at the zenith, uniform temperature conditions (night 
time or complete cloud cover), and zero wind. With the reflector at $60^{\circ}$ to the zenith the tolerances on the mesh section were doubled.

Details of the constructional features of the Parkcs tclescope (Fig. 1) have been given elsewhere [1]. It will suffice here to recall that the dish mesh surface is divided into numerous panels which are adjustable (the central solid part was adjustable during construction but is no longer so). Early consideration was given as to the most satisfactory method of monitoring the adjustment of the dish surface during construction and of surveying the surface at intervals therearter. Various techniques were investigated and the most satisfactory proved to be a theodolite survey with the theodolitc mounted at the vertcx.

The mounting for the theodolite consisted of a rigid metal pyramid bolted to the dish surface at the vertex, the theodolite trunnion axis being approximately $1200 \mathrm{~mm}$ above the surface. Two theodolites were available, a Kern DKM2 for the basic survey at the zenith position and a spccial1y-constructed theodolite, manu-

[1] I.G. Bowen, and H.C. Minnett, "The Austra1ian 210-ft Radio Telescope", Proc. IRE (Aust.) vol. 24, no.2, pp.98-105; February 1963. 
facturcd by $\Lambda$ skania-Werke, for measurements of deformations of the dish surface, relative to the basic survey, when the radio telescope was tilted from the zenith by angles of up to $60^{\circ}$.

Approximately 700 targets were distributed over the mesh surface of the dish; these consisted of small cones located at the adjustment points of the mesh pancls, in a series of rings concentric with the vertex. The linear distance of each target from the vertex was measured by means of calibrated steel tapes.

During the construction of the telescope (carricd out, of course, with the dish at the zenith) the theodolite technique proved extremely satisfactory, the adjustments to the surface of the mesh being simply those of bringing each target to its calculated correct angular position.

The obscrvations required to carry out a complete survey of the dish surface at the zenith to the best accuracy were time-consuming but gave excellent results. Measurements of the deflections of the surface when the dish was tilted proved to be an extremely uncomfortable task, were far less accurate and much more lengthy.

It was shown, however, that the specification had been very closely adhered to; subsequent gain 
measurements at wavelengths of $20 \mathrm{~cm}$ and $10 \mathrm{~cm}$ confirmed this and held promisc of satisfactory performance at shorter wavelengths.

In 1962 the Nationa1 Aeronautics and Space Administration of the U.S.A. made available a grant for a study of the engincering aspects of the performance of the Parkes telescope. As part of this programme, the authors undertook an investigation aimed primarily at obtaining more precise information on the changes in surface shape during tilting of the dish; the basic accuracy requirement for the measurement was to be $1 \mathrm{~mm}$, normal to the surface, at the rim (approximately $30,000 \mathrm{~mm}$ from the vertex) and, if possible, proportionally within. This corresponds to an accuracy on theodolite angles from the vertex of better than 7 seconds of arc on all targets.

\section{PRELIMINARY INVESTIGATIONS}

The problem was considered afresh from all aspects and the capabilitics of a number of possible techniques were critically assessed. The conclusion reached was that a theodolite-type survey from the vertex provided the most feasible and practical method of obtaining the required information within the specified accuracy. 
Since the equivalent deflection normal to the dish surface for a given change in radial distance of a surrace tarect from the vertex is relatively small (at the rim the factor is 1:4) and since the structure of the dish is such that the calculated values for these radial movements are themsclves very small, the problem essentially became onc of measuring small changes in angle. It was obvious also that the equipment and techniques should be such as to enable a large number of observations to be /madc in a relatively short time as telescope time available for this work would be very limited; in other words, some automation was indicated. Furthermore, although measurements would normally be made at night during a period of thermal stability of the dish structure, it must be possible also to operate in daylight and perhaps assess the thermal effects.

Based on these requirements an automatic photographic technique was worked out in outline and this is illustrated in Iig. 2. The proposal consisted of putting a beaded reflector behind each surface target, illuminating the target by means of a spot1ight, observing the target with a telescope and projecting an image of the target and the telsicope araticulc on to a $35 \mathrm{~mm}$ film in an automatic camera. By placing the alignment telescope below the dish surface at the vertex with its axis along the dish axis, it would bepossible for the telescope and camera 
to be rigidly fixed and the only items requiring rotation would be a mirror and the spotlight; both the mirror and the spotlight would, of course, need to be provided with adjustment of angle in elevation. The technique would be to set the mirror for a given ring of targets, pinotograph all targets in that ring with the dish pointing to the zenith and then obtain similar sets of photographs of the same ring at various inclinations of the dish. Measurements would then be made on the photographic ncgatives of the relationships of the images of the targets with respect to the images of the alignment telescope araticule and hence obtain, by comparisons with the zenith set, measurements of the movements of the target normal to the line of sight.

liwo preliminary cxperiments were carried out: the rirst, toassess the feasibility of the photography, the sccond, to determine the form of spindle and bearirg for the rotating mirror.

It was found that adequate resolution could be obtained in the photography using Ilford HP3 film, a single 48 watt spot1ight and $1 / 25$-second exposure; in the rinal cquipment, this was changed to Ilford FP3, two spot1igits and $1 / 15-$ sccond exposure with control of light intensity to suit the ring of targets being meastred. 
The directional reflective property of the beaded reflector bchind the target was such that the exposure was controlled almost cntirely by the intensity of the spotlights and the exposure for any given target could be the same both day and night. It was also found that with the alignment telescope it was possible to use the ocular virtually as the camcra lens with negligible distortion.

Initially it was thought that the very high precision required for the mirror spindle would require the design of a special bearing. It was decided, fortunately, to try first a pair of commercial bearings (Fischer $70 \mathrm{~mm}$ Super Precision Bearing MM214W1-CR) and an experimental spindle assembly was constructed and subjected to test. Although the axis of rotation was found to vary in position during one revolution (eccentricity of approx. $0.00007 \mathrm{inch}$ ) this variation was found to follow the same pattern in each and every revolution within 0.00001 inch as measured radially in the plane of the bearing and within 0.00015 inch axially. It was therefore decided to use this bearing in the final equipment. 


\section{NUTOMATIC SURVEY INSTRUMENT}

The Cinal design of the automatic survey instrument was of necessity influenced by the fact that it had to fit into the existing structure. Certain details in the design of the mounting are not, therefore, as kinematically sound as one would desire; they do not, however, alter the general concept nor do they have a seriously adverse affect on the accuracy of the instrument. The instrument has been located at the vertex in place of the original pyramid for the Kern and Askania theodolites and the general arrangement is shown in lig. 3 .

$\Lambda$ very robust pyramid carrics the spindle and mirror assembly. The spindle bearings are spaced 24 inches apart to reduce any effects of the bearing inaccuracies on the stability of the axis of rotation. The spindle itself is in the form of a tube and at the upper end has a finished bore concentric with the axis of rotation and of such a sizc that an alignment telesconc or collimator unit can be preciscly located in it. The mirror assembly is mounted on a precision-ground spigot locating in this finished bore of the spindle. The mirror axis is square to the spindle axis and the mirror may be adjusted in clevation angle by a worm and sector drive; a perforated fixed disk and spring 
$-\mathrm{cd}$

load/plunger arm facilitate the setting of the mirror angle for any particular ring of targets and a locking device ensures that the mirror angle cannot change during a series of observations. The mirror unit is, of course, locked to the spindle.

The pyramid is located and held rigidly to the surface of the dish by means of 24 holding-down bolts operating in opposition to an equal number of adjusting screws. This latter arrangement was necessary as the axis of the mirror spindle had to be aligned with a reference axis of the radio telescone defined by two special targets, one in the floor of the vertex room ( $7 \frac{1}{2} \mathrm{ft}$ below dish surface) and onc in the floor of the hub room ( $15 \frac{1}{2}$ ft below dish surface).

The two spotlights, with their tilting mechanism, are carricd on a turntable mounted on an independent and much lighter tripod. Special slip rings mounted under the turntable and with multiple contacts (to climinate arcing) transmit the $12 \mathrm{~V} \Lambda \mathrm{C}$ supply to the spotiights. The spotlights are used witi a rheostat in scrics to give control of $1 \mathrm{ight}$ intensity, since by varying this intensity in an appropriate manner it is possible to obtain the correct cxy osure with only one shutter speed setting; this simplifies the shutter operating mechanism considerably. 
Rotation of the mirror spindle and of the lights is effected through a gear box located below the pyramid bottom plate. $\Lambda$ fractional horsepower motor drives continuously into the gear box and two synchronized outputs are coupled, through flexible couplings, to the mirror spindle and lights turntable respectively. Intermittent motion is imparted to these outputs through a single Geneva mechanism giving 60 dwells (maximum number of targets in a ring) per revolution of the outputs. In addition, a cam in the gear box operates a microswitch in the camera circuit, thereby operating the shutter; the time for which the microswitch is depressed is the actual cxposure time and with the cam rotating at 15 r.n.m. a dwe 11 or $6^{\circ}$ gives $\frac{1}{15}$ second exposure. The approximate sequence times are 1 sccond to index from one target to the next with a 3-sccond dwell on target, the shutter being triggered after $2 \frac{1}{2}$ seconds of this dwe 11 period. It takes approximately 4 minutes to complete a ring of targets and obtain 60 exposures; this time is less than the minimum time of 6 minutes required to tilt the dish from 0 to $60^{\circ}$.

The telescope and camera are mounted below the bottom plate of the pyramid ona very rigid bracket (maximum rigidity in the plane of tilt). The telescope, which is an N1ignment Telescope made by Rank Taylor llobson, 
is mounted in vee blocks on a plate bolted to the main bracket and is provided with screw adjustments to enable the optical axis of the telescope to be aligned with the axis of rotation of the mirror spindle.

The camera, made by D. Shackman and Sons (Model $\Lambda$ C1/100/R/Mk2), has a reflex vicwfinder which, with the aid of a low-power magnifier, cnables the telescope graticule and the image of the target to be focussed satisfactorily in the film plane. It takes a $100 \mathrm{ft}$ length of $35 \mathrm{~mm}$ film which gives approximately 750 exposures at one loading.

If only a few exposures are required for a special purpose, it has proved more satisfactory to replace the large Shackman camera with a standard $35 \mathrm{~mm}$ reflex camera body and standard cassettes. A simple slecve-type adaptor is all that is required to attach the standard camera body to the alignment telescope; in our casc, we used an Asahi Pentax camera body with right-angle viewfinder attachment.

The survey instrument was mounted in a special stand for testing purposes and for transport from the Division's laboratories in Sydney to the telescope at Parkes, a distance of some 200 miles. Figure 4 shows the unit in the test stand; the $35 \mathrm{~mm}$ camera shown is an carlicr model than that finally fitted and to which 
reference has already been made.

Laboratory testing was not extensive owing to the necessity of getting the instrument to Parkes for installation during one of the half-yearly overhaul periods on the radio telescope. Some functioning tests were made, however, and in particular the repeatability of the illst rument was determined by setting up a specimen target at a distance of $30 \mathrm{ft}$, and taking a series of photographs over a number of revolutions of the spindlc. No detectable variation of the target image position was observed and this indicated that repeatability was certainly not worse than the resolution of this particular experiment, approximately 5 seconds of arc.

\section{SURFACE TARGETS}

The original conical targets used in the construction of the dish were found to be a little short for good photography and not we11-sinaped. They were replaced by new anodized black aluminimum targets, as shown in fig. 5 , all being individually identified.

The headed reflector behind the target gave some troulle at first. This was due to a number of variables in the material, all of which were resolved with the cooperation of the manufacturer's representatives. 
It is cssential for good photographic results that the bead sizc should be as small as possible. In Australia the best available material appears to be Scotchlite Imperial White Self-adhesive, but it is necessary to check-test it as there are variations from batch to batch. A11 the reflectors have been sprayed with Scotchlite 700 clear lacquer to give weather protection; there is no significant loss of the directional reflectivity but the lacquer itself provides specular reflection which leads to a marked deterioration in image quality. This was climinated quite simply by setting each reflector out of square to the line of sight by a few degrees.

A11 the survey measurements are made to the conical points of the survey targets which are mounted at the adjusting points of the purlins supporting the mesh surface panels. The targets therefore constitute the primary survey network from which separate interpo1ation measurements can be made to assess individual pancl deformations. $\Lambda$ s part of this separate study, a simple dial comparator has been made (Fig. 6(a)) to measure the height of each target point above the mesh surface in its immediate vicinity. A similar comparator has also been made to measure the heights of targets above the supporting purlin (Fig. 6(b)) . 


\section{THE PHOTOGRAPHIC NEGATIVE}

As already stated the instrument is designed to operate with only one shutter setting, namely $1 / 15$ second, and control of exposure is made by means of a rheostat in the power supply to the spotiights.

A series of exposure tests were carried out in conjunction with light meter readings of the incident light falling on each target. The result of thesc tests showed that adequate negatives could be obtained with one shutter speed using Ilford FP3 (fine grain panchromatic) film developed in Kodak D76 developer and with the lights controlled to give sensibly the same light flux at cach ring of targets. This control was achieved by adjustments ranging from the use of one spotlight only at $9.3 \mathrm{~V}$ to both spotlights at $12.4 \mathrm{~V}$.

For the measurements on the photographic negative a Durst Photographic En1arger, type M35 with $50 \mathrm{~mm} \mathrm{f} 3.5$ lens, having an en1argement range of $x 2$ to $x 16 \frac{1}{2}$ is used. The image of the target (see Fig. 5 inscrt), is, in every case, magnified to twice full target size. To facilitate this adjustment, the widths of all target reflectors on a selected radial purlin have becn made equal within close limits. The magnification to be used with a given ring can then be set simply by adjusting the reflector image to fit accurately between 
two parallel lines spaced by twice the width of the calibrated reflectors.

Distance measurements are made from the tip of the target image to the centre of the graticule using a special scalc having divisions spaced at $2 \mathrm{~mm}$ intervals. Thus each division measured on the image corresponds to $1 \mathrm{~mm}$ at the target normal to the line of sight. Alignment of thc scale to give the correct direction for measurement is taken from the vertical sides of the reflectors.

\section{INSTALLATION IN THL RADIO TELESCOPE}

Before installing the actual survey instrument in April 1964 certain preliminary work had to be completed.

Earlier measurements of dish surface deformations with tilt, using the special Askania theodolite, had revealed significant movements in the solid surface of the dish surrounding the vertex. This caused the original theodolite pyramid to deflect from its datum rosition by up to 1 minute of arc at $60^{\circ}$ zenith angle. l' overcome this, a reinforcing tube was placed under the vertex with rigid connections to the underside of the dish surface and to the floor of the vertex room (see ligs. 3 and 7). This stiffened the structure very considerably as shown by the figures quoted in Section 7.2. 
Two glass graticule targets had been installed during construction to define the geometric axis of the dish. One of these was immediately below the vertex of the dish and the other in the floor of the hub room (Fig. 7). The upper of these had to be removed to accommodate the new instrument and in any case it was considered desirable to re-establish the axis. The vertex glass target was first replaced by a target on the floor of the vertex room; this is a crossed-wire target to obviatc any error due to wedge and/or tilt effects when viewing past this target down to the hub room target. On the solid part of the dish, at a radius of $2050 \mathrm{~mm}$, are 4 equispaced reference targets, identified as the $\beta$ targets, and the vertex was re-established as the intcrscction of taut wires stretched across opposite pairs of thesc targets. The dish was then tilted until thcodolite obscrvations indicated that the plane through the "C" ring targets (radius of $11,700 \mathrm{~mm}$ ) was horizontal; this was provisionally taken as the criterion for the gcomctric axis of the dish being vertical. By means of a spccial mounting fixture and a Rank Taylor Hobson Micro-alignment telescope, a vertical line of sight passing through the intersection of the wires joining the 6 targets was established. The vertex and hub room targets were then adjusted to be on this 1ine of sight 
and were securely locked in position.

The original pyramid was then removed and the new instrument installed so that the axis of the mirror spindlc was coincident with the line through thecentres of the vertex room and hub room floor targets. On completion of the adjustments the unit was secured by tightening the 24 holding-down bolts. A cover was installed around the instrument to give complete weather protection; this cover is in two parts, the bottom part a permanent fixture, the top part being removable for operation of the instrument.

Two stations into which a control box could be plugged as required were established; one station was on the pyramid itsclf and the other alongside the camera inside the vertex room rcinforcing tube. The control box incorporates the switches for the lights, the spindle rotation (including direction), an exposure counter, a single-shot camera operating button and indicating lamps, including one to show when the film in the camera has been exhausted. The rheostat for control of light intensity is mounted inside the vertex room reinforcing tube.

Figure 8 shows the survey instrument, at the vertex, being set up for night observations of dish deformations. 


\section{LVALUATION OF PERFORMANCE}

Certain essential Seatures of the automatic survey instrument were tested immediately after installation and some have subsequently been tested at intervals during the operation of the equipment since that time.

\subsection{Deflections within the Instrument}

The deflections within the instrument itself which are most significant involve the relationship of the tilting mirror and the alignment telescope. The mirror assembly is, when locked for a particular angle setting, a very rigid unit and it was considered that the main source of deflection would be in the spindle bearings, the main pyramid and the telescope and camera bracket.

Initially, this was checked by mounting a microalignment telescope in the vee in place of the normal telescope and a collimator unit in the precision bore of the spindle. The relative angles of these two units were obscrvedat various angles of tilt of the dish and the miximum movement appeared to be 3 seconds of are, which was the limit of resolution of the alignment, telescope and collimator. 
A more precise measurement was made at a later date. The mirror assembly was removed from the main spindle and replaced by a plain precision mirror approximately square to the spindle axis and rigidly attached to the spindle. An autocollimator was located in the vec bracket, in place of the alignment telescope, and angular obscrvations on the mirror werc made at various angles of tilt of the dish. The maximum measured deflection was found to be 4 scconds of arc, at zenith angle of $60^{\circ}$ and is cquivalent to $0.57 \mathrm{~mm}$ at the rim of the dish. This figure is we 11 within the basic accuracy requirement for the instrument; moreover, it represents a largely systematic error which is a function of the dish zenith angle and of target location. For measurements of the highest precision, thercfore, a correction must be applicd to the observed values of the target dericctions.

It is considered that some improvement in the performance of the instrument in this respect could be achicved but this would require fairly extensive structural alterations. 


\subsection{Deflections of the Instrument Relative to the Reference axis}

This was measured by placing a Micro-alignment telescope in the finished bore of the mirror spindle and observing on the reference targets in the floor of the vertex room and hub room at various angles of tilt of the dish. Additional observations were simultancously made on a special crossed-wirc target mounted in the vee bracket in place of the normal telescope. This special target was constructed so that the intersection of its crossed-wires coincided with the position of the optical axis of the normal telescope.

Analysis of the observations on the vee target confirmed, within the accuracy of measurement, the values already obtained for the deflection within the survey instrument itself.

The obscrvations on the floor targets showed deflection which reach a maximum of 3 seconds of arc at the $60^{\circ}$ position. In the plane of tilt the direction of these deflections is the same as those observed within the instrument, in the plane at right angles the direction is opposite to those within the instrument.

It is apparent that the installation of the reinforcing tube has considerably stiffened the structure and has reduced the relative deflection between the 
instrument and reference axis by a factor of 20 . It is possible that the remaining deflection represents a real tilt of the instrument relative to the dish as a whole; for example, due to residual buckling of the solid dish surface immediately surrounding the vertex. In this case, the deflection is one of the component errors of the measuring process. Since it is a substantially systematic function of zenith angle, it could be calibrated and a corrcction applied.

It must be stressed, howexer, that the "reference axis" is defined by floor targets in the tilting part of the telescope and there may be distortions of the order of a few seconds in the hub structure itself. Thus it is not clear that the measured deflection represents a real tilt of the instrument and the matter cannot readily be resolved since it is difficult to establish an absolutely reliable datum within the hub. Until further investigations of this point have been made, it must be assumed that the present environment of the instrument contributed an uncertainty to the measuring process of up to 3 seconds of arc at zenith angle $60^{\circ}$. 


\subsection{Repeatability of Measurements}

$\Lambda n$ important aspect of the performance of the automatic survey instrument is the limits within which measurements made with it will repeat. This was assessed by obtaining six consecutive series of photographs around each of two rings (C at radius of $11,700 \mathrm{~mm}$ and $M$ at radius of $21,600 \mathrm{~mm}$ ), the dish remaining locked at the zenith position for each series. The photographs were taken at night and with almost zero wind, giving good conditions. The negatives werc than measured in the normal way so that the test was really on the repeatability of the whole measuring process - mirror rotation, photography and measurement of the negative using an en 1arger.

Using three standard deviations as a measure of repeatability, it was found that measurements on $\mathrm{C}$ ring repeated within $0.3 \mathrm{~mm}$ and on $M$ ring within $0.5 \mathrm{~mm}$. These figures are equivalent to approximately $5 \mathrm{sec}$ of arc.

$\Lambda$ separate test of one part of the process, the measurements on the negatives, was made. This, of course, is very largely a function of the definition of the target image and is therefore dependent to some extent on the conditions at the dish winen the photographs were taken (for example, certain wind velocities may set 
up vibrations in the dish stricture thus reducing definition on some targets). Reasonably good images were obtained at the time of the tests and with these the repetition of measurements was found to be $0.3 \mathrm{~mm}$ at both ring $C$ and ring $M$. This corresponds to $5 \mathrm{sec}$ and $3 \mathrm{sec}$ of arc respectively.

While not exhaustive, the tests indicate that a substantial part of the overall error iies in the negative measurements. The repeatability of the survey instrument itself is probably of the order of a few seconds of arc.

\subsection{Overall Accuracy}

The overall accuracy of the measuring process is a function of the various factors already discussed. Most measurements involve the difference between two sets of observations as, for example, in determining the surface deflections when the dish is tilied from the zenith to a specific angle. It is appropriate, therefore, to compute the combined repeatability as $\sqrt{2}$ times the repeatability for each single set of obseryations ( 5 seconds of arc) giving 7 seconds of azc. This means that $99.7 \%$ of the individua: aeflection measurements will have an crror due to the random variations in the whole measuring process of less than 7 seconàs of arc. 
The deflections within the survey instrument itself (i.e. internal distortions) and the deflections of the instrument relative to the floor reference targets (i.e. the environmental error), may be combined with the error in the measuring process in two ways.

If all these errors are simply added together, the resultant overall accuracy of an incividual deflection measurement becomes 14 seconds of arc for a dish tilt of $60^{\circ}$; this represents the most pessimistic assessment of the overall accliracy.

The deflections within the survey instrument itself are, however, essentially systematic and may be calibrated. The measurements may, therefore, be corrected by an appropriate value. The overall accuracy is then the resultant of the environmental uncertainty (Section 7.2 ) and the repeatability of the measuring process, giving a maximum value of 10 seconds at a zenith angle of $60^{\circ}$. Further improvement on this figure can be achieved by taking the mean of a series of measurements on the negatives.

It is probably reasonable to assess the overall accuracy of the performance as being generally within the range from 5 seconds at zero zenith angle to 8 seconds at zenith angle $60^{\circ}$. 
8. TYPICAL MEASURIMMENTS WITH TIE INSTRUMENT

Somc typical applications of the automatic survey instrument are described below together with a few of the main results. Details of the various measurements undertaken with the instrument and their corre1be ation with radio performance wil1/given in subsequent papers.

\subsection{De formation of Dish due to Tilting}

The automatic survey camera has been used to obtain values for the deflections, normal to the dish surfacc, of a11 of the targets on that surface. These values have been obtained for zenith angles of $10^{\circ}, 20^{\circ}$, $40^{\circ}$ and $60^{\circ}$, the target positions at zenith angle $0^{\circ}$ being taken as datum.

The time requircd to obtain the photographic record on a single ring of targets at angles of $0^{\circ}, 10^{\circ}$, $20^{\circ}, 40^{\circ}, 60^{\circ}$ and a repeat at $0^{\circ}$ is about 45 minutes and the records for two rings just fit on to one $100 \mathrm{ft}$ recl of film. The time of 45 minutes includes, of course, the time to tilt the dish and also the time required to set the mirror, the spotiights and the focus of the alignment telescope. 
$\Lambda$ typical set of results for a single ring is given in Fig. 9 and a typical contour map of the deflections over the dish surface is shown in Fig. 10 .

The contours arc drawn at intervals of $1 \mathrm{~mm}$ and cxhibit cxcellent symmetry about the vertical (gravitational) plane. The influence of tripod leg loading on dish shape is clearly visible and there is evidence of greater deflections over the intermediate purlins as compared with the purlins supported by the main dish ribs.

\subsection{Moasurcment of Basic Dish Shape}

Thic automatic survey instrument is essentially a device for the measurement of relative dish deflections. Mcans have been provided, however, for mounting the Kern theodolitc so that a survey of the basic dish shape can be made.

$\Lambda$ special pedestal has becn constructed having an accurately machined spigot which locates in the finished borc of the instrument spindle (in place of the mirror asscmbly) and a suitablc mounting platc for the theodolite (Fig. $11(a))$; it is, of coursc, necessary to remove the spotlights when using the theodolite. The dimensions or the theodolite pedestal are such that the height of the theodolite trunnion axis above the vertex is the same 
as when the theodolite was used on the original pyramid.

A full theodolite survey of the targets on the dish surface is extremely time consuming although with carc a very high accuracy, of the order to 1 to 2 scconds of arc, can be obtaincd. $\Lambda$ complete survey could occupy four to five full nights of obscrvation. If a slightly lower accuracy, say approximately 5 secs, is acceptable then the theodolite and camera instrument can be combined to reduce the total time on the dish to about $5 \frac{1}{2}$ hours. The procedure is to measure very carefully by means of the theodolite the angular position of one key target in each ring (i.e. 23 targcts in a11) and then to photograph each ring of targets in turn. In this way the cquivalent thcodolite valucs for every target may be obtained by relating the photograph measurements to the theodolite values on the key targets. This procedure has been carried out but the evaluation of the results has not as yet been completed.

\subsection{Measurement of Jiced Position and Deflection}

The various feeds used on the radio telescone are mounted from a focd platform immediately below the acrial cabin. This red platform can he adjusted axially for best focus and the central section (6 ft in diameter) can be rotated throubl $360^{\circ}$ for polarization measurement: and parallactic angle corrections. 
By removing the mirror assembly from the spindlc of the survey instrument, the alignment telescope can be focussed on a suitable target placed at the centre of the fecd platform. This target was made in the form of a transparent grid graticule with $2 \mathrm{~mm}$ spacing, and was back illuminated. A typical photograph of this target is shown in Fig. 12 .

Using the graticule in the alignment telescope as reference the position of the feed relative to the axis of the survey instrument and the deflection of the feed as the dish is tilted can be readily determined. For this purpose it has been found convenient to use the Asahi pentax (with 20 or 36 cxposure cassettes) in preference to the Shackman camera.

It was found that the angular feed deflection was closely proportional to the sine of the zenith angle and amounts to 3.8 minutes of arc at $60^{\circ}$, corresponding to a linear deflection of $29 \mathrm{~mm}$ at the feed point.

\subsection{Rc1ation of Various Telescope Axes to the Gravitational}

$\underline{\text { Vertical }}$

A useful feature of the survey instrument is that it provides a method for measuring the inclination of the instrument spindle axes to the gravitational vertical, with the dish near zero zenith angle. 
A second pedestal has been made similar to that for the thcodolite, but having a lapped stecl upper surface accurately square to its spigot (see Fig. 11(b)). With this pedestal mounted in the instrument spindle an enginecr's precision level placed on the lapped surfacc gives the inclination of the spindle axis to the gravitational vertical. It has been found that a Carl Zciss (Ioni) Coincidence level is very satisfactory for this purpose and a precision of 2 to 3 scconds of arc is readily attainable.

Combined with a basic dish survey, the use of the level and pedestal cnables the dish axis and feed point to $h$ related to the gravitational vertical. Owing to variatinns in the surface of the azimuth track of the radio telcicope, this relationship changes with azimuth. By taking moasurements at a scries of arimuths through $360^{\circ}$, useful information on track level variations can be obtaincd and, in addition, the inclination of the azimuth axis to the vertical can be computed.

In the Parkes telcscope, the arimuth axis is used as the telescope "vertical" rather than the gravitational vertical, in order to maintain the correct relationship between the equatorial and altazimuth indicators. The technique described therefore provides the 
means for sctting the zcro of the zenith-angle indicator by relating the geometrical axis of the dish to the azinuth axis.

\section{CONCLUSIONS}

The new survey instrument enables the surface deformations of the $210-\mathrm{ft}$ radio telescope to be measured in a relatively short time with an accuracy ranging from 5 seconds of arc at low zenith angles to 8 seconds of arc at zenith angle $60^{\circ}$ (these values correspond to $0.74 \mathrm{~mm}$ and $1.2 \mathrm{~mm}$ respectively at the rim).

It also cnables a detailed survey at zenith angle $0^{\circ}$ to be carricd out very quickly with not too great a loss of accuracy over a full theodolite survey. Measurements of feed position and deflection, of the relationship of the dish to the true vertical and of variations in the position of the dish axis due al1

to azimuth track irregularities can/be obtained relative$1 y$ quickly and to accuracies of 5 seconds of arc or better. 


\section{ACKNOWLEDGMENTS}

The work described in this paper forms part of a study of the engineering aspects of the performance of the Parkes $210-\mathrm{ft}$ Radio Telescope supported by the National $\Lambda$ cronatics and Space Administration grant $\mathrm{NsC}-240-02$

We wish to acknowledge the encouragement given to the project by Dr. E.G. Bowen, Chief of the Division of Radiophysics and Mr. F.J. Lehany, Chief of the Division of Applicd Physics.

We would particularly like to thank Mr. K.J. Loughry of the Division of Applied Physics for his enthusiastic assistance in the construction and operation of the equipment. Our thanks are also due to Mr. II.I. Peddic for preparation of the design drawings and to Miss Lois Martin for the reduction of the data. 


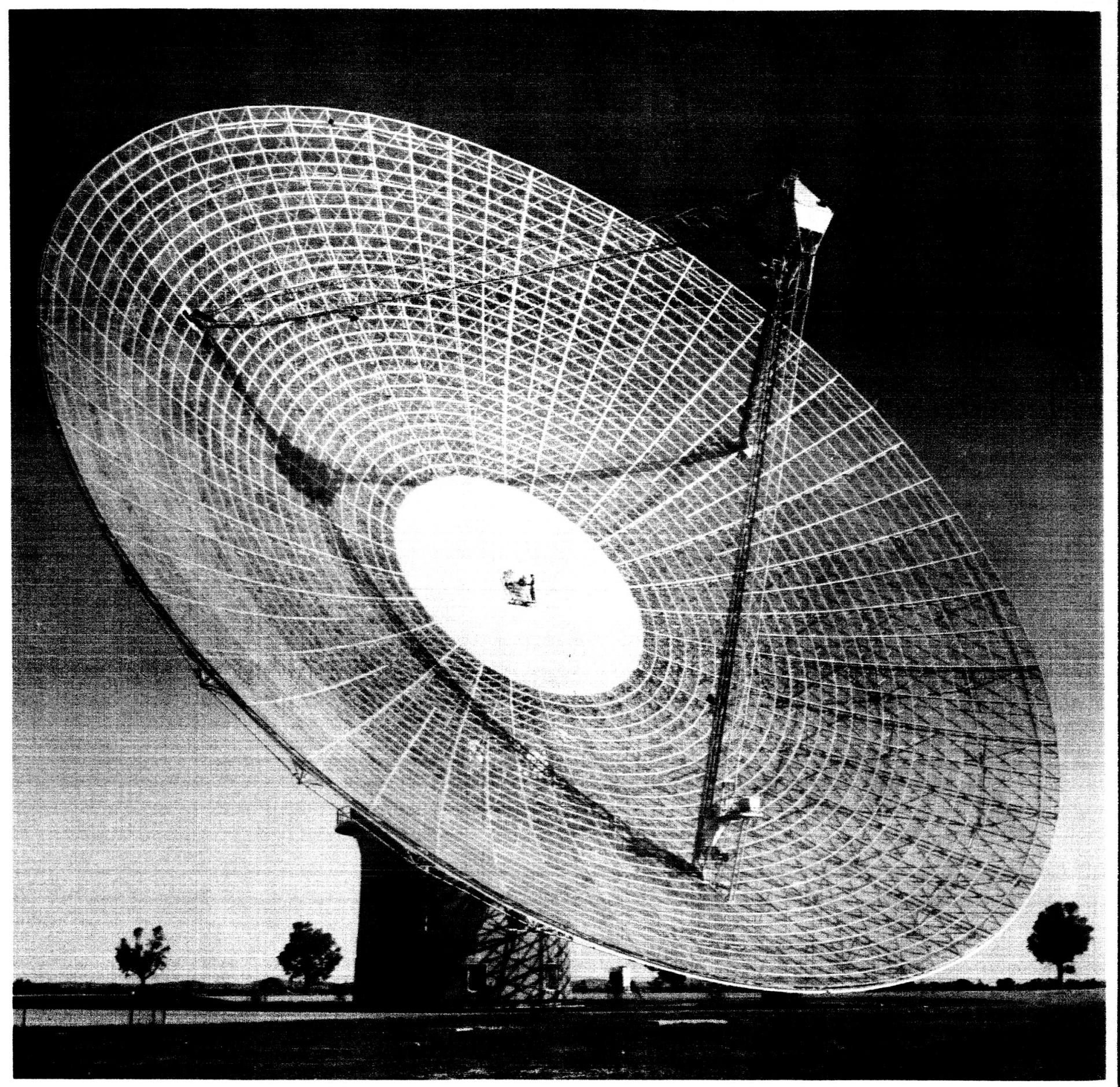

Figure 1.-General view of 210 - ft radio telescope at Parkes with the survey instrument at the vertex. 


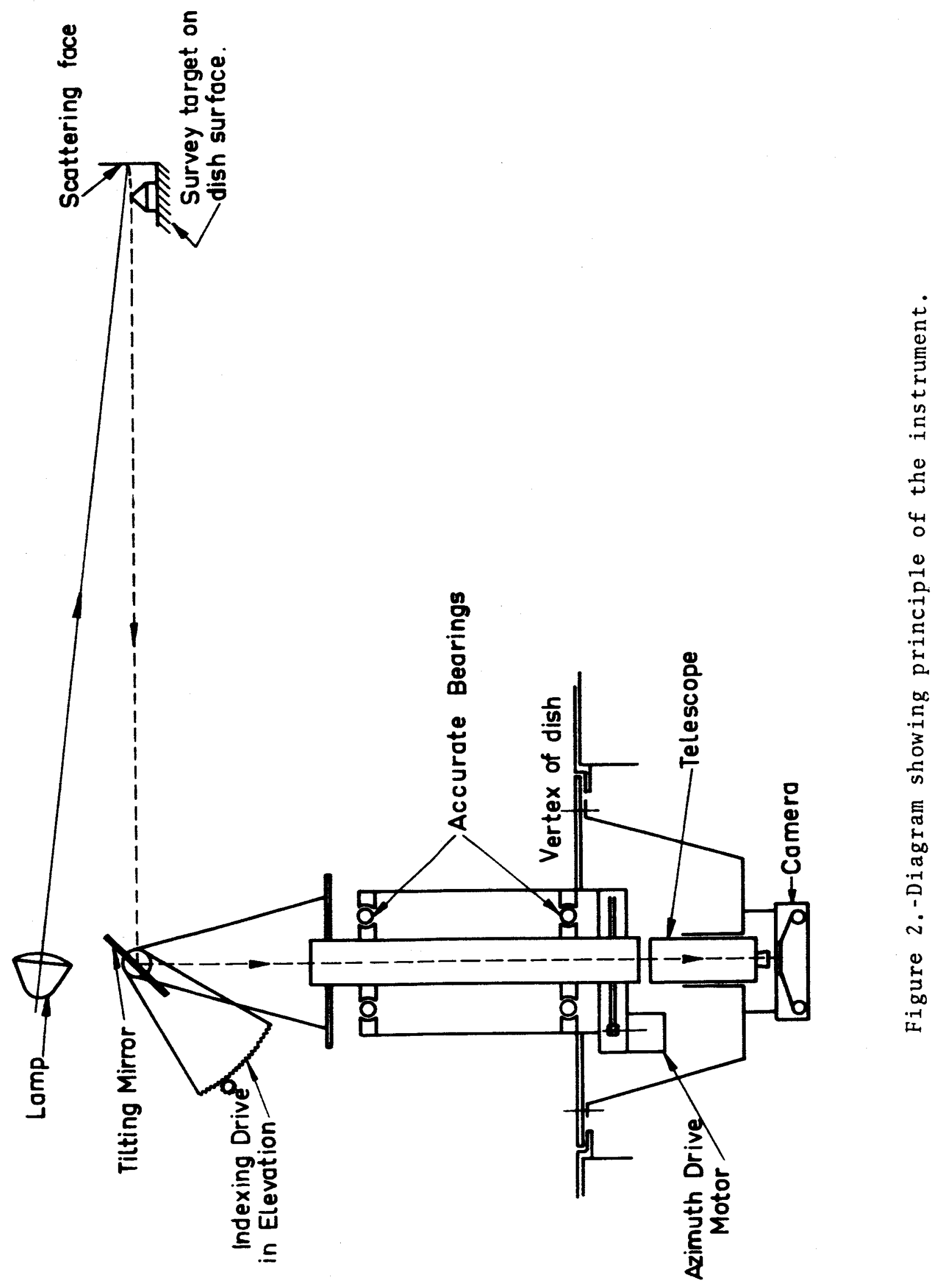




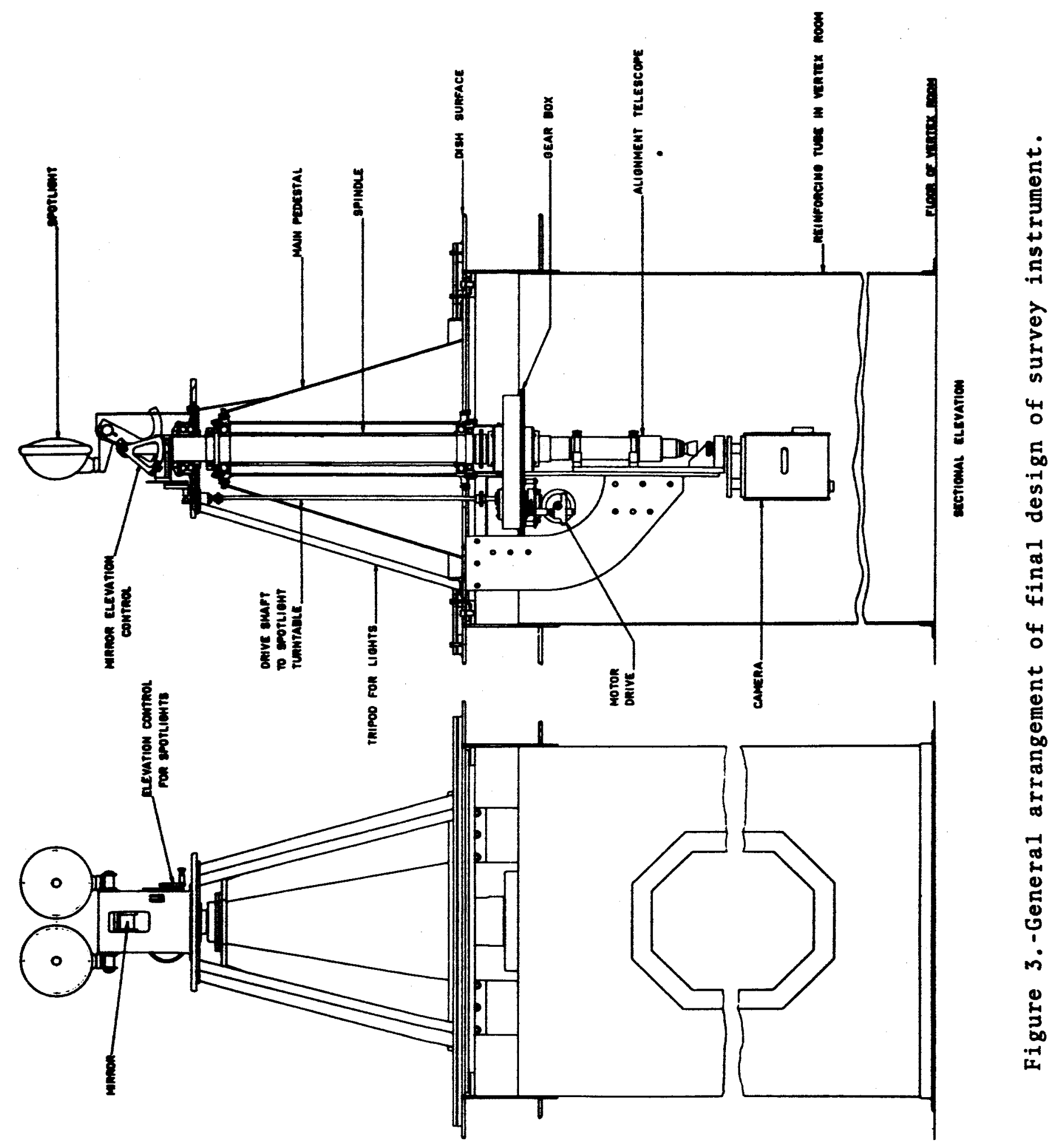



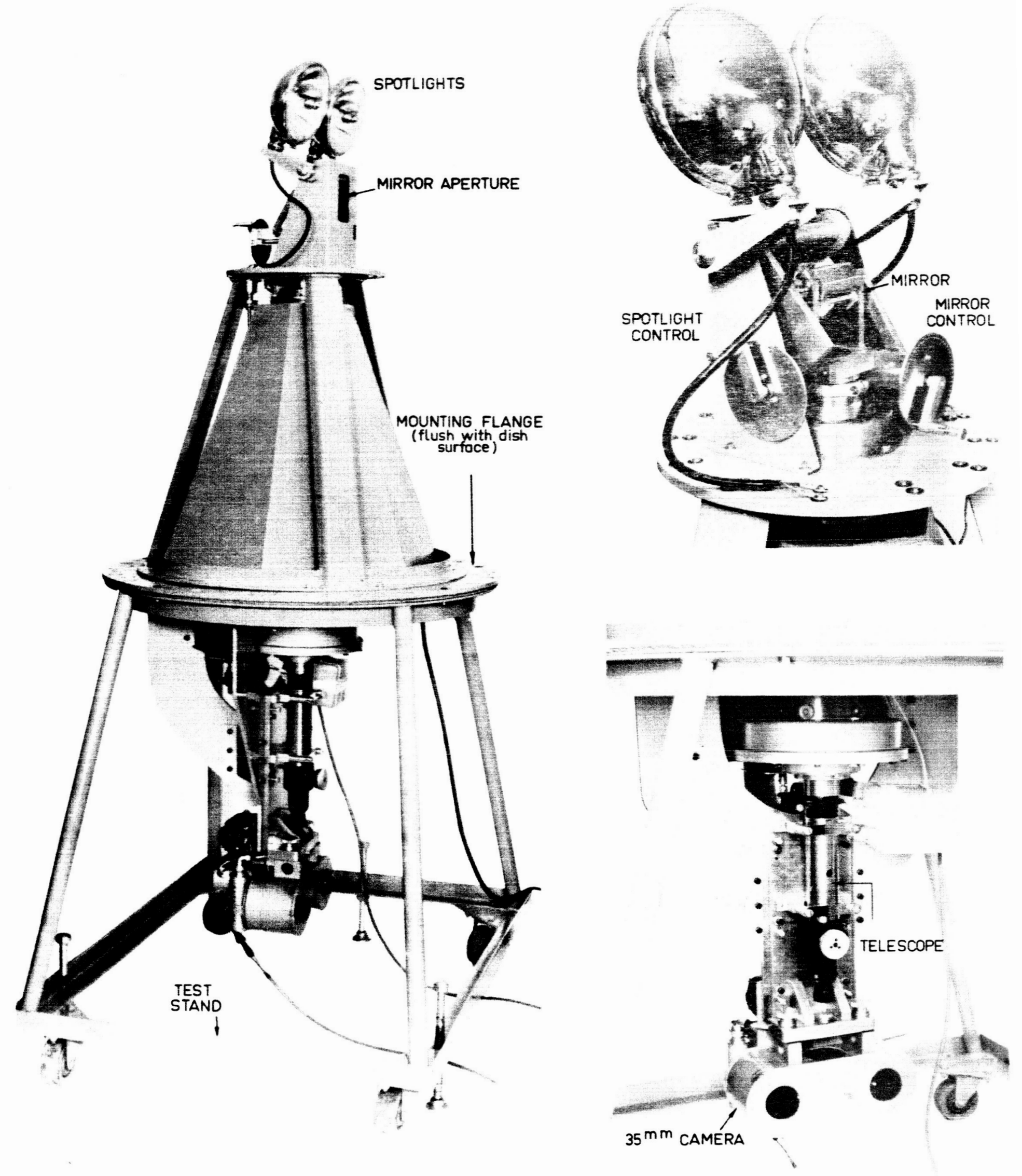

Figure 4.-Survey instrument in test stand. 


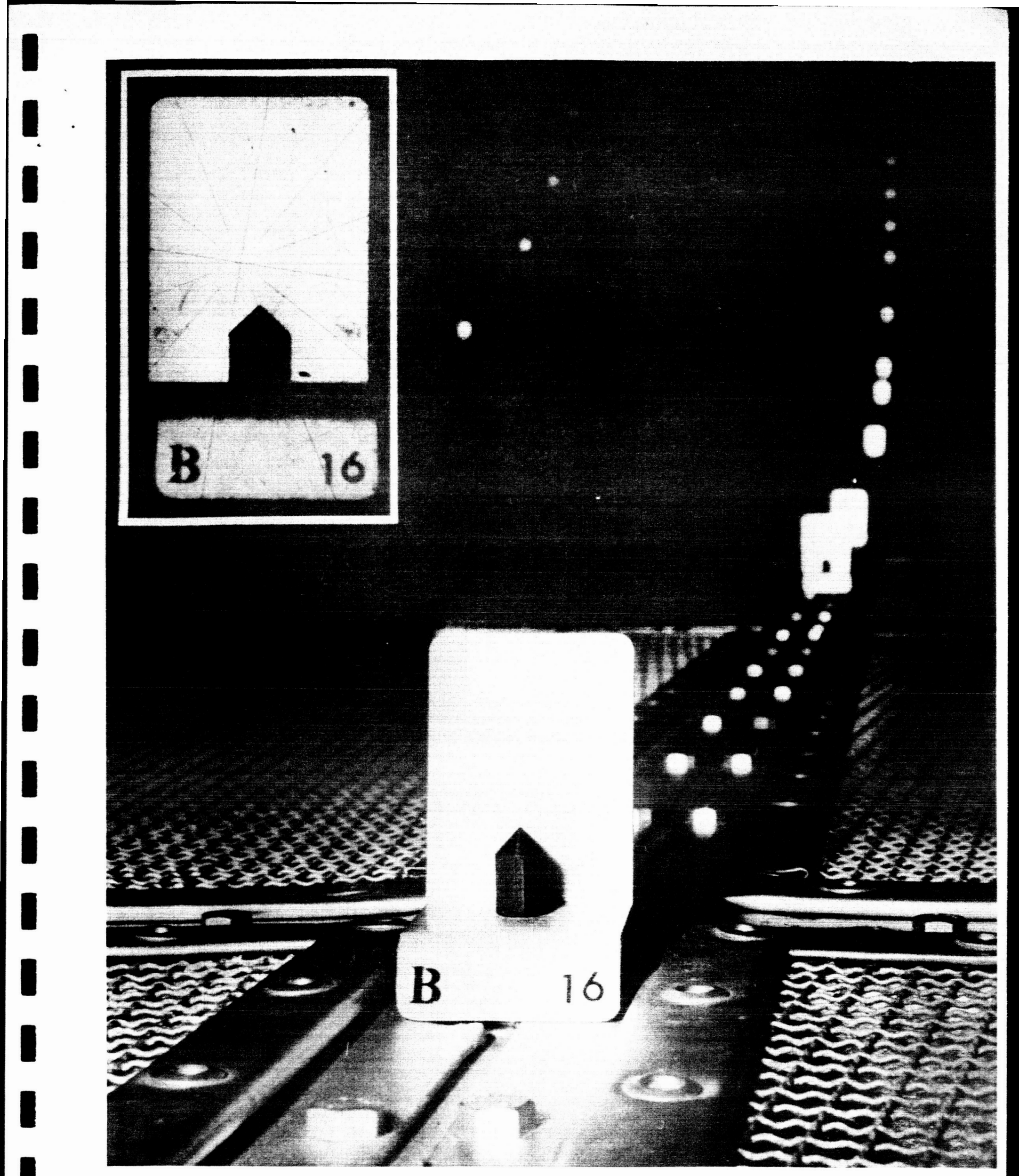

Figure 5.-Surface target and reflector. Inset: Photographic image projected for analysis. 


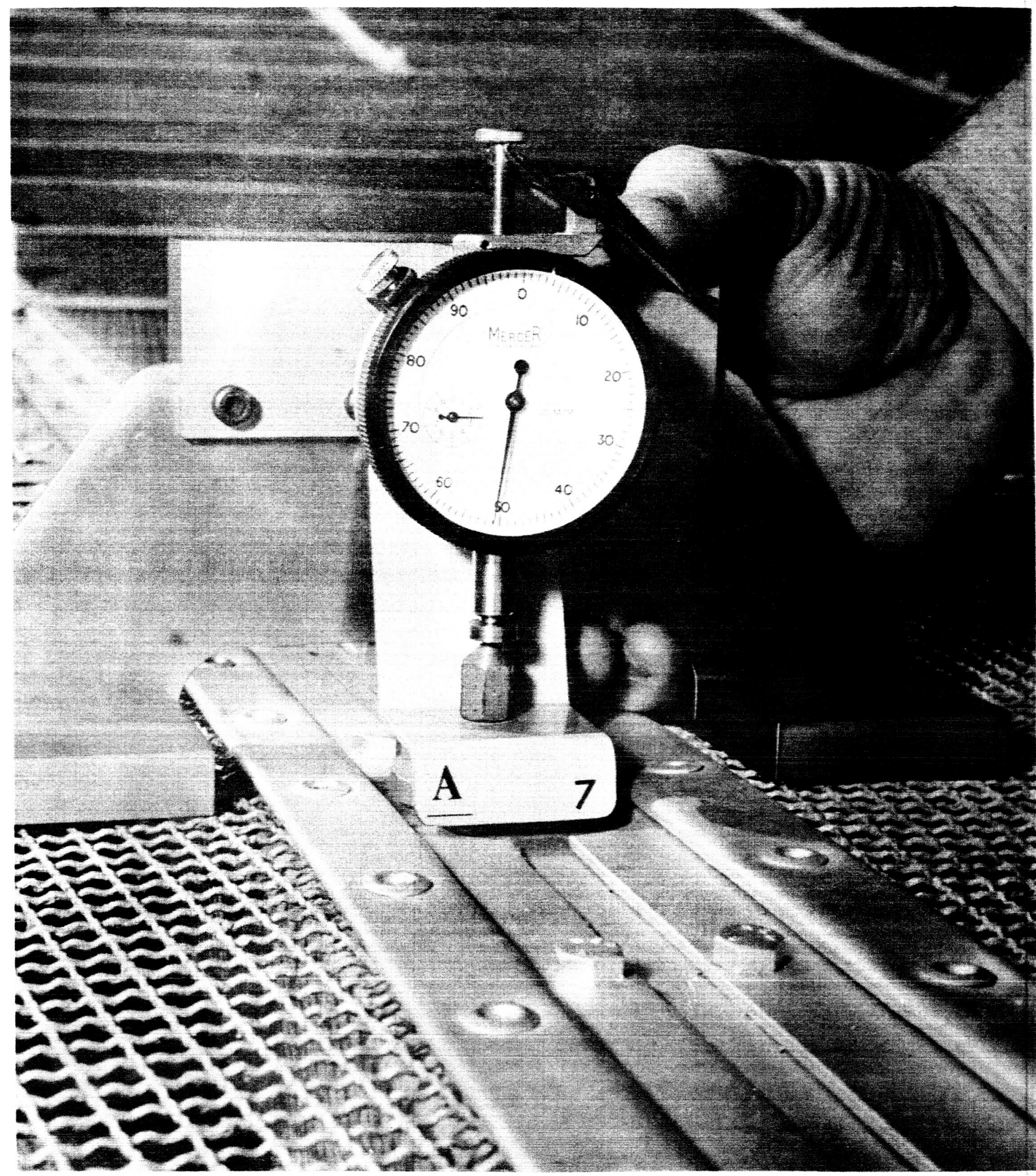

Figure 6b.-Instruments for measuring position of target relative to mesh. 


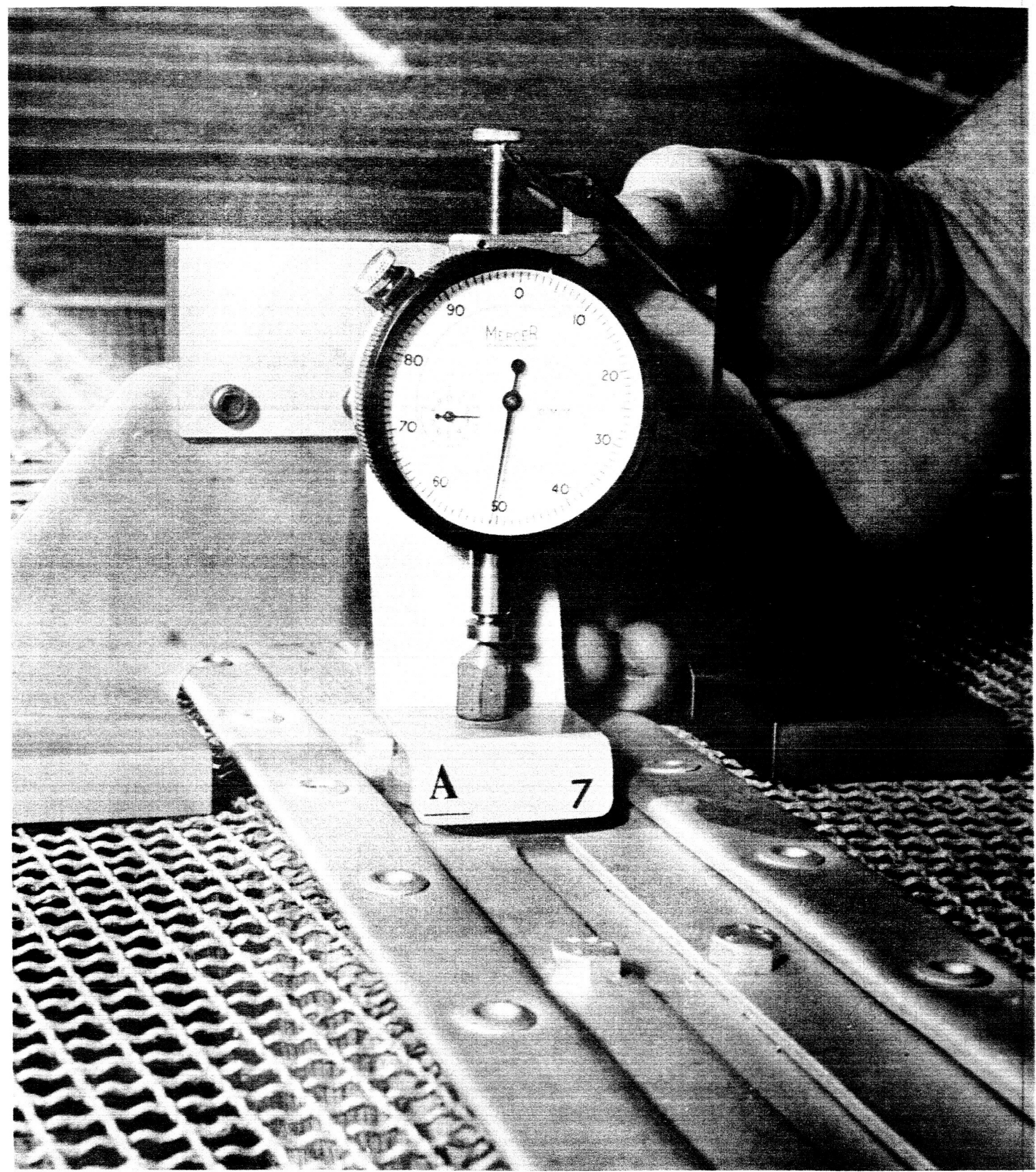

Figure 6b.- Instruments for measuring position of target relative to mesh. 


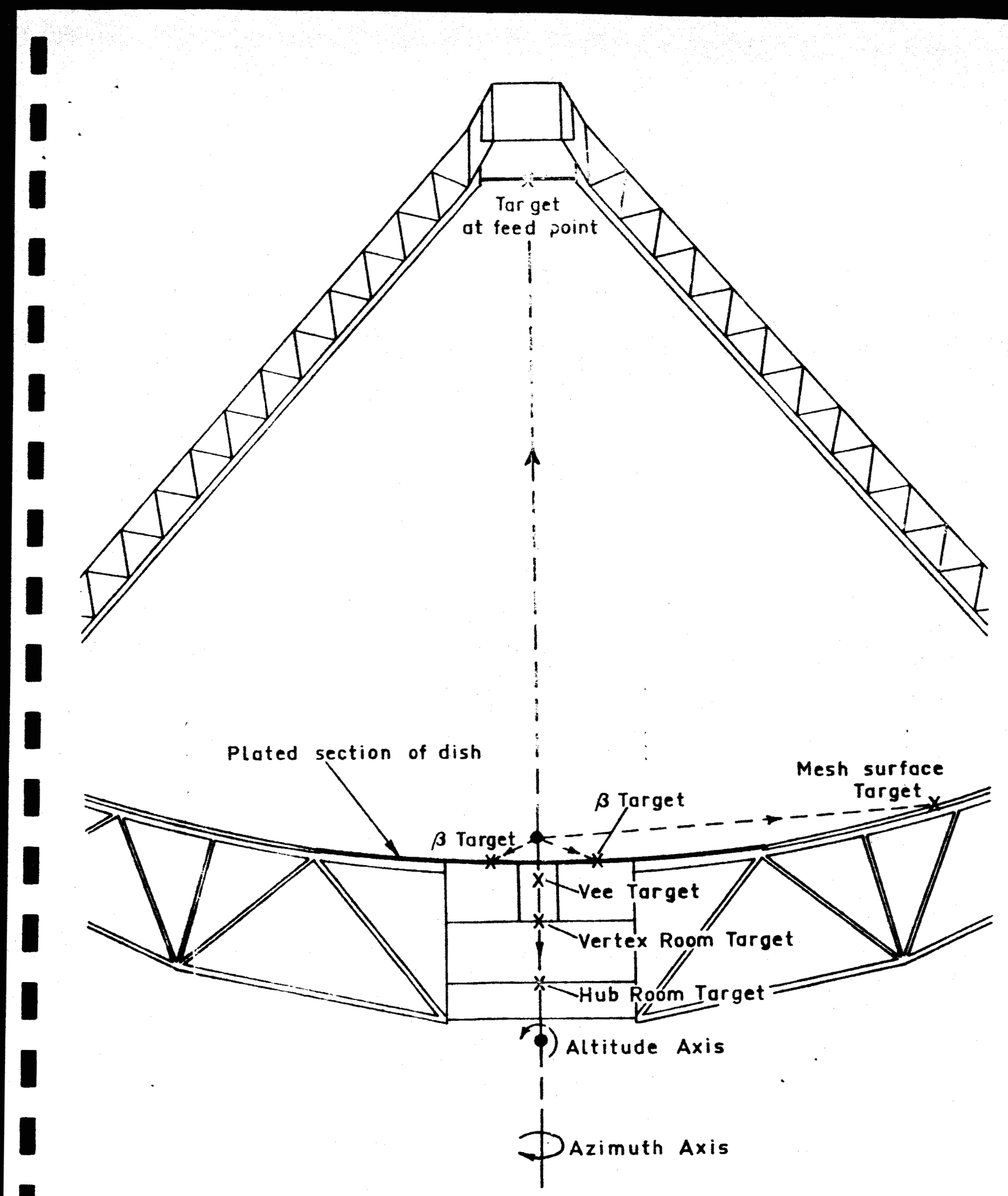

Figure 7.- Positions of targets used with survey instrument 
Figure 8.-Setting up instrment for surface deflection measurements at night. 







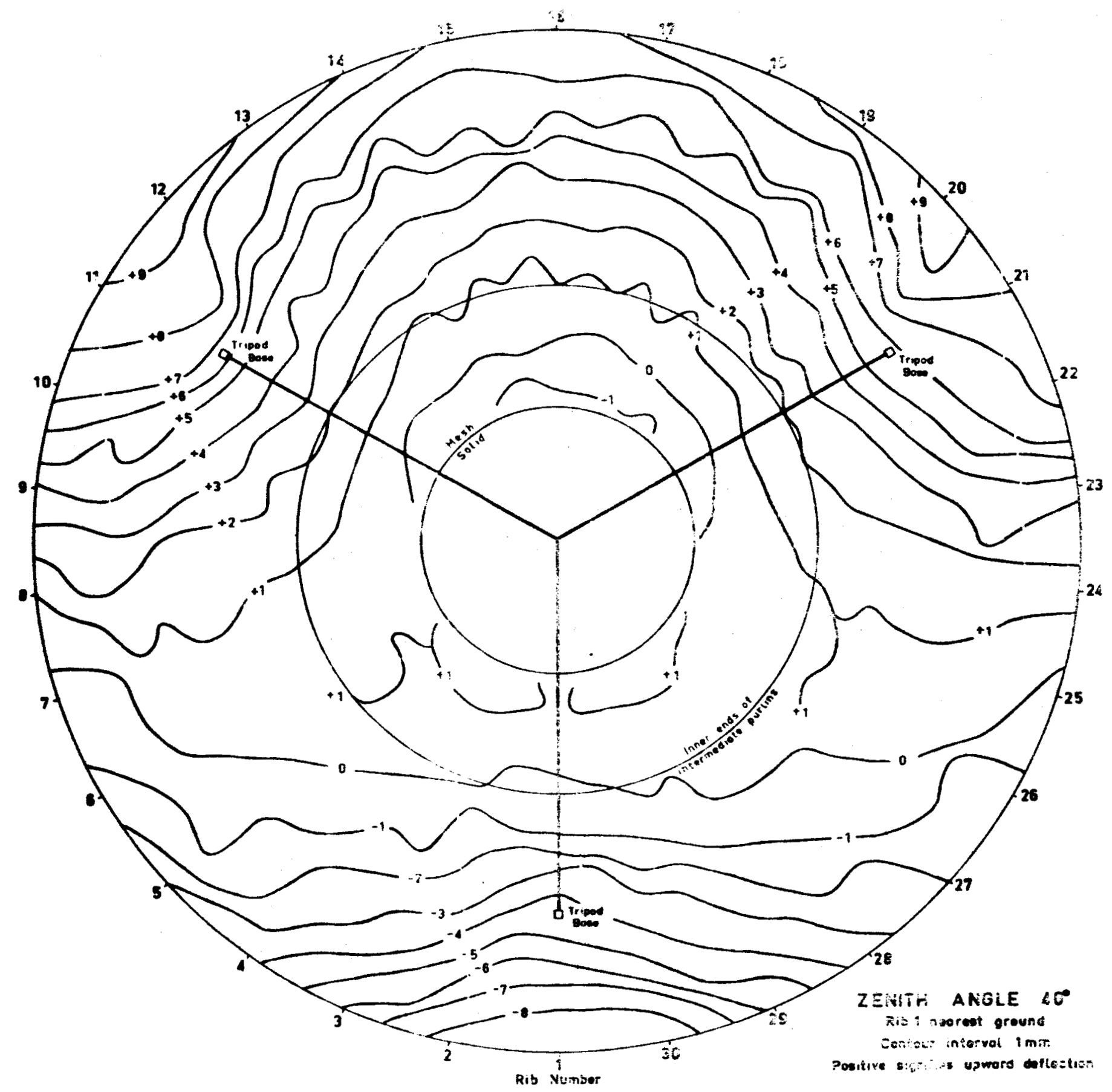

Figure 10.- Typical deflection contours produced by tilting dish to a zenith angle of $40^{\circ}$ 

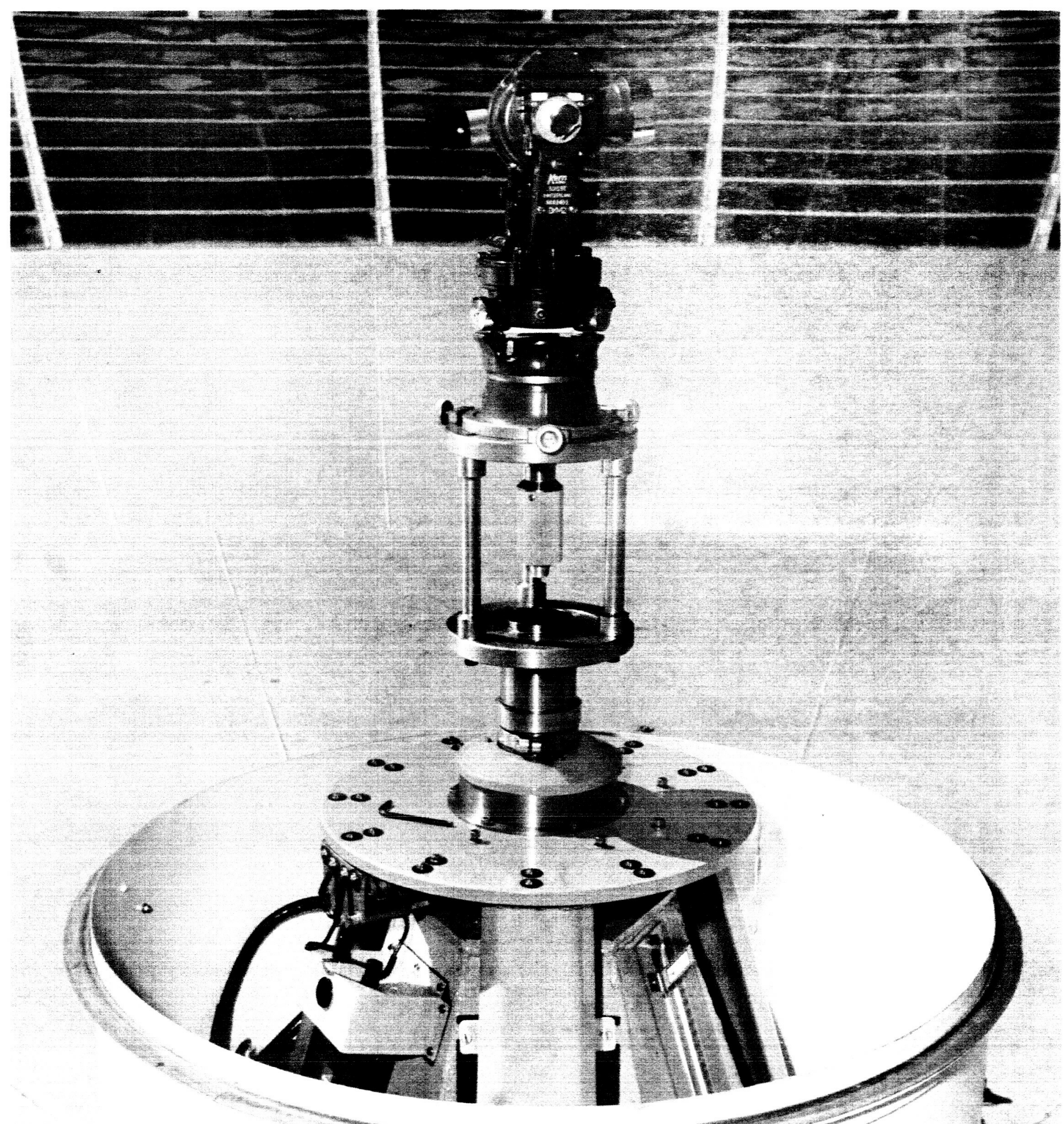

Figure 11a.-Special mounting pedestals for theodolite. 


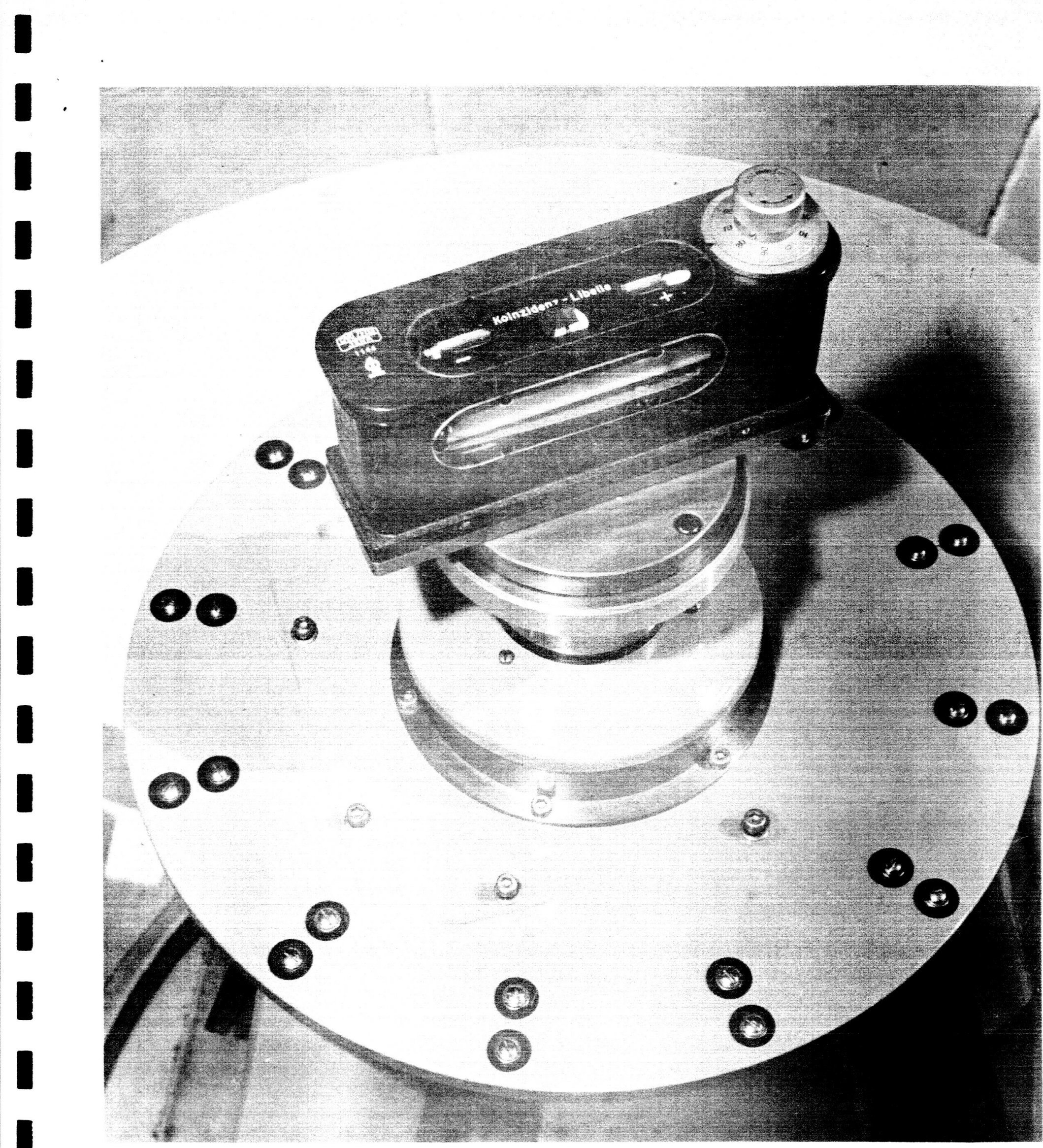

Figure 1lb. Special mounting pedestals for engineer's precision level. 


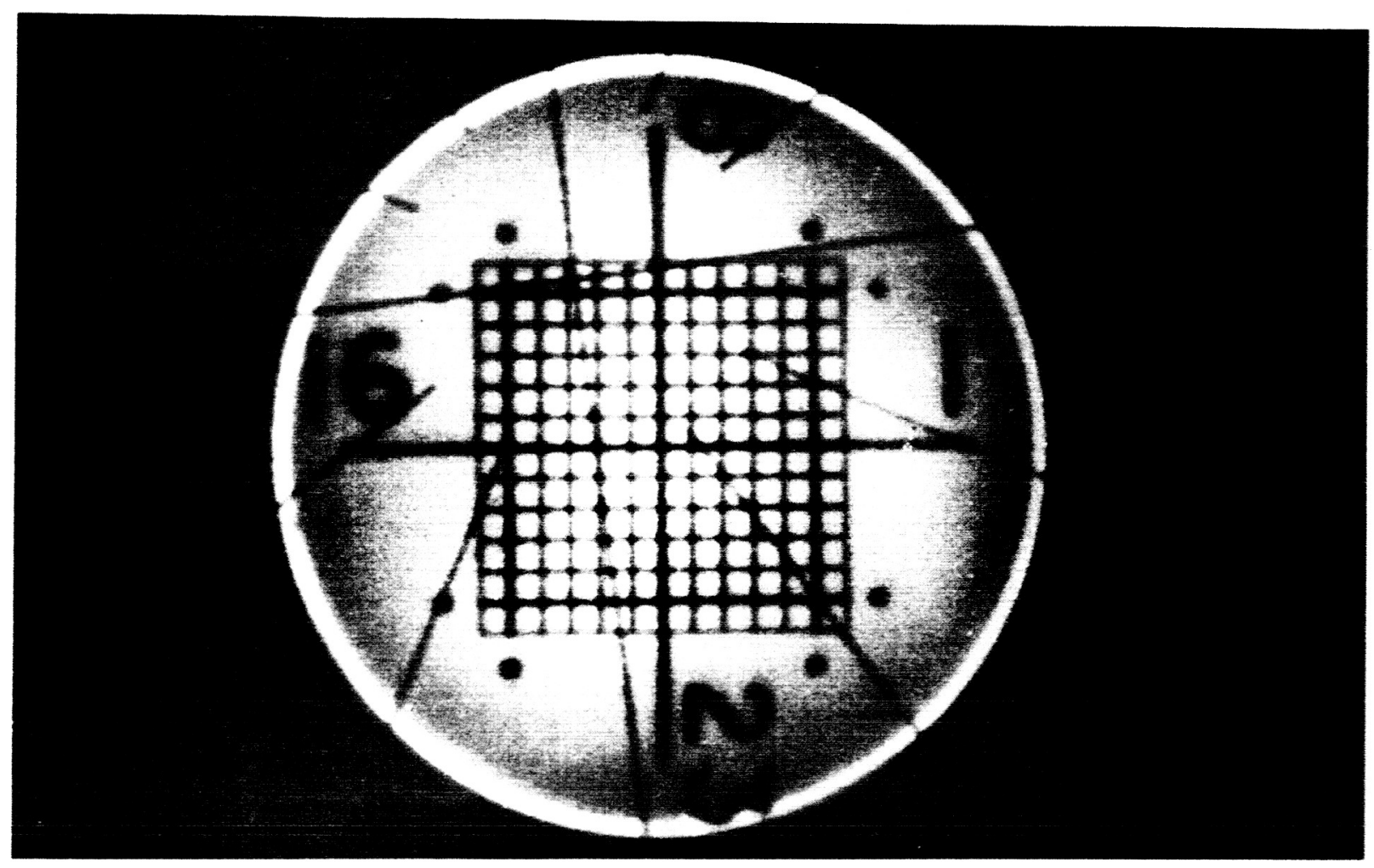

igure 12.-Photograph of special feed target taken with the survey instrument. 